The INL is a

U.S. Department of Energy

National Laboratory

operated by

Battelle Energy Alliance

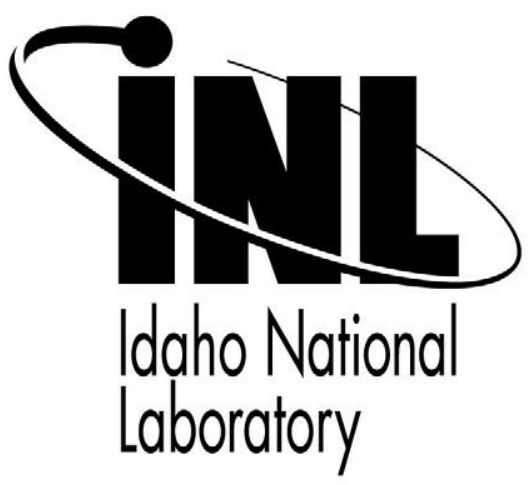

INL/CON-05-00325

PREPRINT

\section{Fabrication And}

Characterization Of Dual

Phase Magnesia-Zirconia

Ceramics Doped With

Plutonia

\section{European Materials Research Society Spring Meeting/Inert Matrix Fuel-10 Workshop}

P. G. Medvedev

J. F. Jue

S. M. Frank

M. K. Meyer

\section{May 2005}

This is a preprint of a paper intended for publication in a journal or proceedings. Since changes may not be made before publication, this preprint should not be cited or reproduced without permission of the author. This document was prepared as an account of work sponsored by an agency of the United States Government. Neither the United States Government nor any agency thereof, or any of their employees, makes any warranty, expressed or implied, or assumes any legal liability or responsibility for any third party's use, or the results of such use, of any information, apparatus, product or process disclosed in this report, or represents that its use by such third party would not infringe privately owned rights. The views expressed in this paper are not necessarily those of the United States Government or the sponsoring agency. 
Fabrication and characterization of dual phase magnesia-zirconia ceramics doped with plutonia

P. G. Medvedev ${ }^{*}$, J. F. Jue, S. M. Frank, M. K. Meyer

Idaho National Laboratory, P.O. Box 1625 Idaho Falls, ID 83415-6160

\begin{abstract}
Dual phase magnesia-zirconia ceramics doped with plutonia are being studied as an inert matrix fuel (IMF) for light water reactors. The motivation of this work is to develop an IMF with a thermal conductivity superior to that of the fuels based on yttria stabilized zirconia. The concept uses the $\mathrm{MgO}$ phase as an efficient heat conductor to increase thermal conductivity of the composite. In this paper ceramic fabrication and characterization by scanning electron microscopy, energy and wavelength dispersive xray spectroscopy is discussed. Characterization shows that the ceramics consist of the two-phase matrix and $\mathrm{PuO}_{2}$-rich inclusions. The matrix is comprised of pure $\mathrm{MgO}$ phase and $\mathrm{MgO}-\mathrm{ZrO}_{2}-\mathrm{PuO}_{2}$ solid solution. The $\mathrm{PuO}_{2}$-rich inclusion contained dissolved $\mathrm{MgO}$ and $\mathrm{ZrO}_{2}$.
\end{abstract}

\title{
PCS codes
}

28.41.Bm, 81.05.Je, 81.05.Mh, 28.41.Kw.

\section{Keywords}

Inert matrix fuel, plutonium disposition, magnesia, zirconia.

\footnotetext{
* Corresponding author. Tel. +1-208 533 7199; fax: +1-208 533 7863; e-mail address: pavel.medvedev@inl.gov.
} 


\section{Introduction}

Advanced fuel cycle initiative (AFCI) is being pursued by the United States Department of Energy with a four-prong objective: recovery of energy from spent nuclear fuel (SNF), reduction of the inventory of civilian plutonium, reduction of the toxicity and heat load of stored SNF, and more effective use of the SNF repository. AFCI's mission is to develop and demonstrate technologies that enable the transition to a stable, longterm, environmentally, economically and politically acceptable fuel cycle.

Use of existing light water reactors (LWR) as a neutron source to fission plutonium and transmute minor actinides provides a near term opportunity for very effective inreactor disposition of these surplus nuclear materials [1]. A need for a non-fertile matrix material that can be safely used in LWR fuels as plutonium and minor actinide dilutant drives material development research in this field.

Yttria stabilized zirconia (YSZ) is the most evolved candidate for use in IMF. Both steady-state [2] and transient [3] irradiations of YSZ-based IMF have been performed. Material properties of YSZ have been closely examined $[4,5]$. Out-of pile irradiation studies designed to understand the mechanism of radiation damage have been completed [6]. Neutronic feasibility of YSZ-based IMF has been also assessed [7] complemented by core burnup calculations and accident analyses [8]. Despite its excellent radiation resistance, compatibility with reactor materials and good neutronic properties, low thermal conductivity is the main disadvantage of YSZ. According to a recent analysis [7] fuel centerline temperature of the YSZ-based IMF may be $100 \mathrm{~K}$ higher than the limit specified for LWRs. Safe use of YSZ as a matrix in LWR fuel is only possible if a 
reactor is operated at a lower power or if fuel pellets feature central voids. Both measures increase the cost and decrease the feasibility of plutonium disposition.

Use of composites containing a phase with a higher thermal conductivity could improve performance characteristics of zirconia-based IMF. Use of $\mathrm{MgO}$ as such a phase has been proposed $[9,10]$. It has been shown $[10]$ that dual phase $\mathrm{MgO}-\mathrm{ZrO}_{2}$ ceramics have the thermal conductivity superior to that of $\mathrm{UO}_{2}$ and have notable resistance to the water at the temperature of $573 \mathrm{~K}$ and pressure 8.6 MPa, making them attractive for use as an IMF matrix. Development of IMF based on $\mathrm{MgO}-\mathrm{ZrO}_{2}$ ceramics continues at Idaho National Laboratory with the support of the AFCI. The present paper describes results of the first experiment to fabricate dual phase magnesia-zirconia ceramics doped with plutonia as a potential IMF form for use in LWRs.

\section{Fabrication}

Dual phase magnesia-zirconia ceramics doped with plutonia were fabricated from the oxide powder mixture using conventional pressing and sintering techniques. The fabrication process was based on the earlier work [10] that dealt with non-radioactive materials. The flow diagram of the fabrication process is shown in Fig. 1.

Pre-weighed amounts of magnesia and magnesium zirconium oxide powders were combined with water in a beaker. The weight of water was approximately 3 times greater than the weight of the powders combined. The water and powder mixture was stirred using a magnetic stirring bar for $6 \mathrm{~h}$. The slurry was dried in air at $353 \mathrm{~K}$ for $5 \mathrm{~h}$. The resulting powder was transferred into an alumina crucible and heat-treated at $1273 \mathrm{~K}$ for 
$5 \mathrm{~h}$ in a high temperature tube furnace. The ramp-up and ramp-down rates were $10 \mathrm{~K}$ $\min ^{-1}$. Upon cool-down, zinc stearate (Fisher Scientific Fair Lawn, NJ Z-78-4, lot 871095 , UPS grade) in the amount of $1 \%$ by weight was mixed into the powder using a mortar and a pestle. The powder was then pressed into pellets with a force of $13.34 \mathrm{kN}$ using a cylindrical die of $12.72 \mathrm{~mm}$ diameter. Resulting $\mathrm{MgO}-\mathrm{ZrO}_{2}$ pellets weighing $3.8986 \mathrm{~g}$ and $3.3571 \mathrm{~g}$ were transferred into a glovebox. Once in the glovebox, the pellets were ground and $1.0265 \mathrm{~g}$ of $\mathrm{PuO}_{2}$ powder was mixed in using a mortar and pestle. The powder was then pressed into pellets with a force of $44.45 \mathrm{kN}$ using a cylindrical die of $12.72 \mathrm{~mm}$ diameter. Resulting pellets were ground into powder using a mortar and pestle. The powder was passed through a sieve with an aperture size of 250 $\mu \mathrm{m}$. The mixture was pressed again into pellets with a force of $13.34 \mathrm{kN}$ using a cylindrical die of $12.72 \mathrm{~mm}$ diameter. The pellets were placed into an alumina crucible and sintered in air for $7.5 \mathrm{~h}$ at $1973 \mathrm{~K}$ in a high temperature box furnace. The ramp-up rate was $10 \mathrm{~K} \mathrm{~min}^{-1}$ up to 1273 and $5 \mathrm{~K} \mathrm{~min}^{-1}$ from 1273 to $1973 \mathrm{~K}$. The ramp-down rate was $10 \mathrm{~K} \mathrm{~min}{ }^{-1}$. The pellets were cooled in the furnace after sintering.

Magnesium oxide was procured from Cerac Incorporated (Milwakee, WI, item M1017, lot X25111, typically $99.95 \%$ pure). Magnesium zirconium oxide supplied by Alfa Aesar (Ward Hill, MA, stock 12343, lot C01E, $99.7 \%$ metals basis) was used as a source of zirconia. Use of magnesium zirconium oxide facilitated obtaining a homogeneous distribution of $\mathrm{MgO}$ and $\mathrm{ZrO}_{2}$ in the final product. 


\section{Characterization of dual phase magnesia-zirconia ceramics doped with plutonia}

\subsection{Visual inspection, dimensions, weight and density}

Two ceramic pellets were fabricated. Photographs of the pellets are shown in Fig. 2. As-sintered pellets are shown in Fig. 2a. Pellet cross-section exposed by cutting a pellet with a diamond saw is shown in Fig. 2b. Each pellet featured one crack near one face as illustrated in Fig. 2c. The crack was probably caused by density gradients developed during pressing.

The pellets were weighed and measured with a caliper. Results of the measurements are shown in Table 1. Pellet diameter was measured three times: in the mid-pellet and near each face. Pellet hourglassing developed during sintering was manifested by diameter decrease in the mid-pellet region.

Pellet density values derived from weight and volume and measured by water immersion technique are included in Table 1. The pellet density was significantly lower than that of $\mathrm{MgO}-\mathrm{ZrO}_{2}$ ceramics studied in the earlier work [10]. $\mathrm{MgO}-\mathrm{ZrO}_{2}$ ceramics containing 50 wt. $\%$ of $\mathrm{MgO}$ had the density of $4.39 \mathrm{~g} \mathrm{~cm}^{-3}$ measured by water immersion.

\subsection{Scanning Electron Microscopy}

Scanning electron microscopy (Zeiss DSM960A digital scanning electron microscope), energy and wavelength dispersive x-ray analyses (Oxford Instruments, 
Freemont, CA) were carried out with an objective to identify the phases present in the ceramics and to determine chemical composition of each phase. Previous fabrication and characterization studies [10] established that $\mathrm{MgO}-\mathrm{ZrO}_{2}$ and $\mathrm{MgO}-\mathrm{ZrO}_{2}-\mathrm{Er}_{2} \mathrm{O}_{3}$ systems containing from 40 to $70 \mathrm{wt} \%$ of $\mathrm{ZrO}_{2}$ and $7 \mathrm{wt} \% \mathrm{Er}_{2} \mathrm{O}_{3}$ sintered in air at $1973 \mathrm{~K}$ consisted of two phases: zirconia-based cubic solid solution and pure cubic magnesia. The amount of magnesia dissolved in the zirconia-based cubic solid solution phase was 13-17 mol. \%. Erbia dopant preferentially dissolved in the zirconia phase. Presence of pure $\mathrm{MgO}$ phase in the ceramics had a positive effect on their thermal conductivity. The same effect is desired in the $\mathrm{MgO}-\mathrm{ZrO}_{2}-\mathrm{PuO}_{2}$ system. Thus, understanding the behavior of $\mathrm{PuO}_{2}$ dopant in the $\mathrm{MgO}-\mathrm{ZrO}_{2}$ system is of particular importance.

To produce a sample for the scanning electron microscopy (SEM) the pellet was cut with a diamond saw yielding a disk approximately $2 \mathrm{~mm}$ thick. The disk was broken up to produce smaller fragments by tapping with a pestle. One of the resulting fragments was mounted in the epoxy and manually polished with the silicon carbide paper of 600 , 800 , and 1200 grits. The polishing time was kept to a minimum in order to reduce the personnel radiation exposure. The sample submitted for analysis is shown in Fig. 3.

Fig. 4 shows key microstructural features identified in the sample: a two-phase matrix (Fig. 4a) and a $\mathrm{PuO}_{2}$-rich inclusion (Fig. 4b). The matrix was found to consist of pure $\mathrm{MgO}$ phase (dark phase in Fig. $4 \mathrm{a}$ ) and $\mathrm{MgO}-\mathrm{ZrO}_{2}-\mathrm{PuO}_{2}$ solid solution (light phase in Fig. 4a). Except for the greater porosity, the microstructure of the matrix was found to be virtually identical to that observed in $\mathrm{MgO}-\mathrm{ZrO}_{2}$ and $\mathrm{MgO}-\mathrm{ZrO}_{2}-\mathrm{Er}_{2} \mathrm{O}_{3}$ systems [10]. The $\mathrm{PuO}_{2}$-rich inclusion shown in Fig. $4 \mathrm{~b}$ contained $\mathrm{MgO}$ and $\mathrm{ZrO}_{2}$ with $\mathrm{PuO}_{2}$ being a dominant component. The columnar grains surrounding the $\mathrm{PuO}_{2}$-rich inclusion were 
believed to be formed due to significant variation of $\mathrm{ZrO}_{2}$ solubility in $\mathrm{PuO}_{2}$ with temperature. Examination of the $\mathrm{PuO}_{2}$-rich end of the $\mathrm{PuO}_{2}-\mathrm{ZrO}_{2}$ phase diagram [11] revealed that the solubility of $\mathrm{ZrO}_{2}$ in $\mathrm{PuO}_{2}$ increases from 20 to $60 \mathrm{~mol} \%$ with the increase of temperature from 1473 to $1973 \mathrm{~K}$. Therefore, this variation in solubility caused diffusion of $\mathrm{ZrO}_{2}$ into the $\mathrm{PuO}_{2}$ particle during the furnace ramp-up and sintering, and rejection of $\mathrm{ZrO}_{2}$ by $\mathrm{PuO}_{2}$-rich particle during furnace ramp-down. Rejection of $\mathrm{ZrO}_{2}$ by the $\mathrm{PuO}_{2}$-rich particle caused particle densification which led to the formation of a gap between the particle and the matrix observed in Fig. $4 b$.

Energy Dispersive X-ray Spectroscopy (EDS) was used to determine chemical composition of the phases present in the ceramics. Typical EDS spectra are shown in Fig. 5. As evident from Fig. 5, the matrix Pu content is higher in the vicinity of $\mathrm{PuO}_{2^{-}}$ rich inclusions. This observation suggests that the solubility limit of $\mathrm{PuO}_{2}$ in the matrix locations away from the inclusions was not reached. Thus, observed undesirable inhomogeneity is possibly due to inadequate mixing rather than the limited solubility of $\mathrm{PuO}_{2}$ in the matrix.

Detailed EDS results are shown in Table 2. EDS spectra were taken in 15 locations in $\mathrm{MgO}-\mathrm{ZrO}_{2}-\mathrm{PuO}_{2}$ grains, 10 locations in $\mathrm{MgO}$ grains, and 5 locations in a $\mathrm{PuO}_{2}$-rich inclusion. Thus, the numbers in Table 2 are the averages and the standard deviations of these multiple measurements. It should be noted that our EDS system is not capable of quantifying the $\mathrm{Pu}$ content. As follows from Table 2, very small amounts of $\mathrm{ZrO}_{2}$ were detected in the $\mathrm{MgO}$ grains. This fact was attributed to the presence of $\mathrm{ZrO}_{2}$ in the neighboring $\mathrm{MgO}-\mathrm{ZrO}_{2}-\mathrm{PuO}_{2}$ grains and possibly to the contamination of the surface of 
the $\mathrm{MgO}$ grains during polishing. Wavelength dispersive spectroscopy (WDS) did not detect dissolved $\mathrm{ZrO}_{2}$ and $\mathrm{PuO}_{2}$ in $\mathrm{MgO}$. Detection limit of WDS was $200 \mathrm{ppm}$.

\section{Conclusions}

Dual phase magnesia-zirconia ceramics doped with plutonia were fabricated and characterized by SEM, EDS and WDS. Ceramics were found to consist of the two-phase matrix and $\mathrm{PuO}_{2}$-rich inclusions. The matrix was comprised of pure $\mathrm{MgO}$ phase and $\mathrm{MgO}-\mathrm{ZrO}_{2}-\mathrm{PuO}_{2}$ solid solution. The $\mathrm{PuO}_{2}$-rich inclusion contained dissolved $\mathrm{MgO}$ and $\mathrm{ZrO}_{2}$. Based on the characterization work it was concluded that the fabrication process must be modified to achieve homogeneity of the product, reduce porosity, and produce an acceptable fuel form. Improved mixing and calcination of $\mathrm{PuO}_{2}$ powder together with $\mathrm{MgO}$ and $\mathrm{ZrO}_{2}$ will be utilized during fabrication of the next batch of the ceramics.

The results of this study provide valuable insight on the phase relations in the MgO$\mathrm{ZrO}_{2}-\mathrm{PuO}_{2}$ system. The study established that neither $\mathrm{PuO}_{2}$ nor $\mathrm{ZrO}_{2}$ dissolved in the highly thermally conductive $\mathrm{MgO}$ phase. By remaining free from dissolved species, the $\mathrm{MgO}$ phase is expected to maintain its high thermal conductivity acting as efficient means of increasing the thermal conductivity of the entire ceramic composite. 
Fig. 1. Flow diagram for fabrication of $\mathrm{MgO}-\mathrm{ZrO}_{2}-\mathrm{PuO}_{2}$ ceramics.

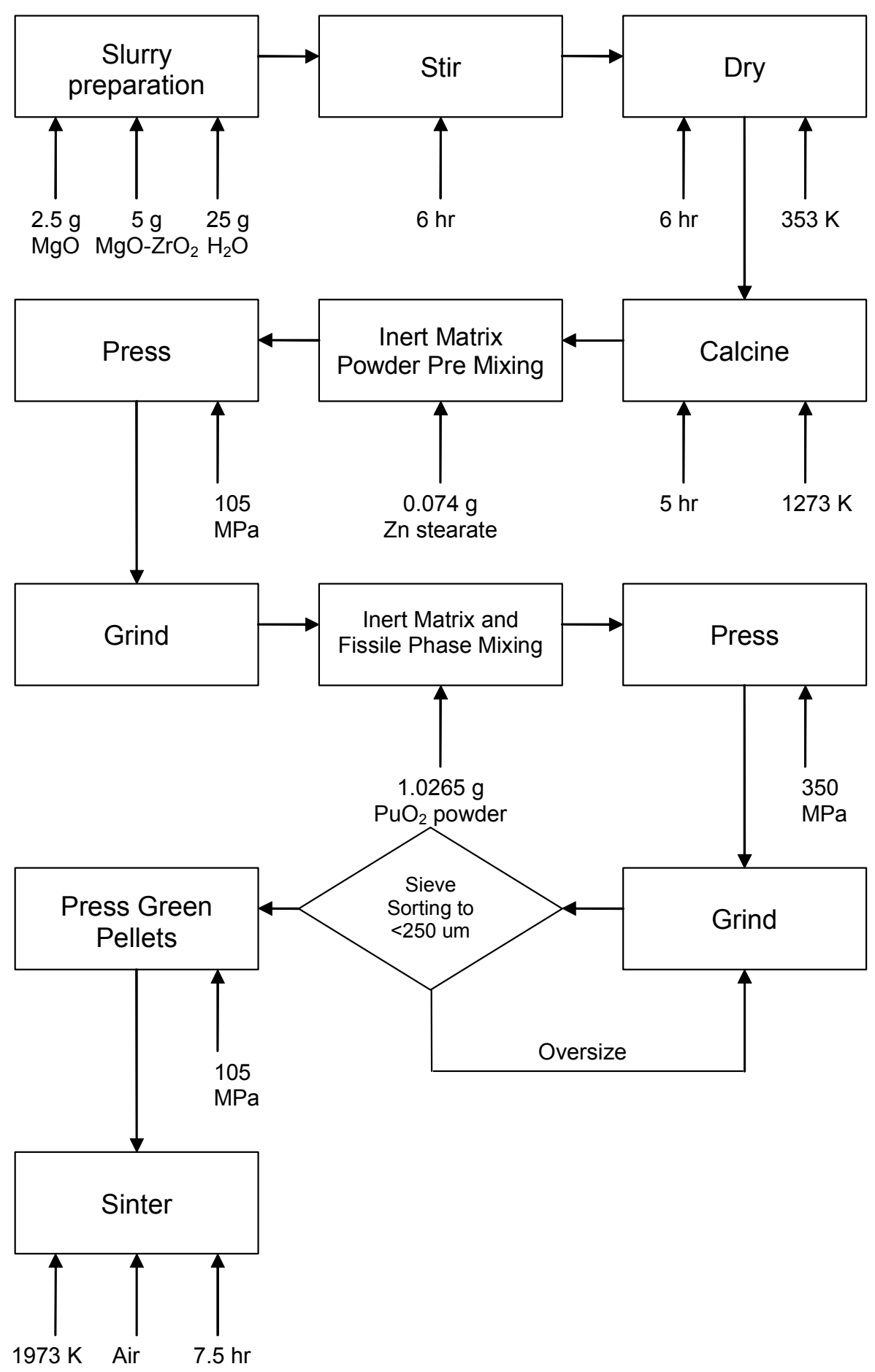


a)

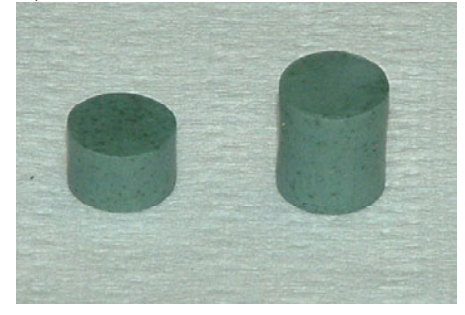

b)

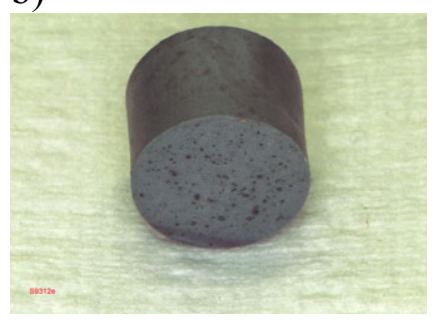

c)

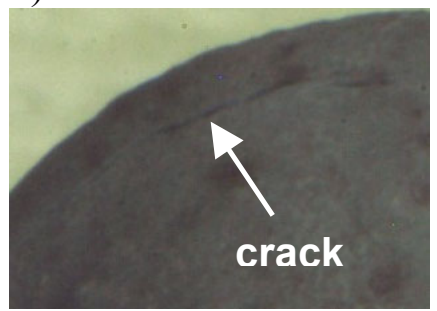

Fig. 2. Fabricated $\mathrm{MgO}-\mathrm{ZrO}_{2}-\mathrm{PuO}_{2}$ ceramic pellets. a) as-sintered pellets, b) pellet cross-section, c) crack near the face of the pellet. 


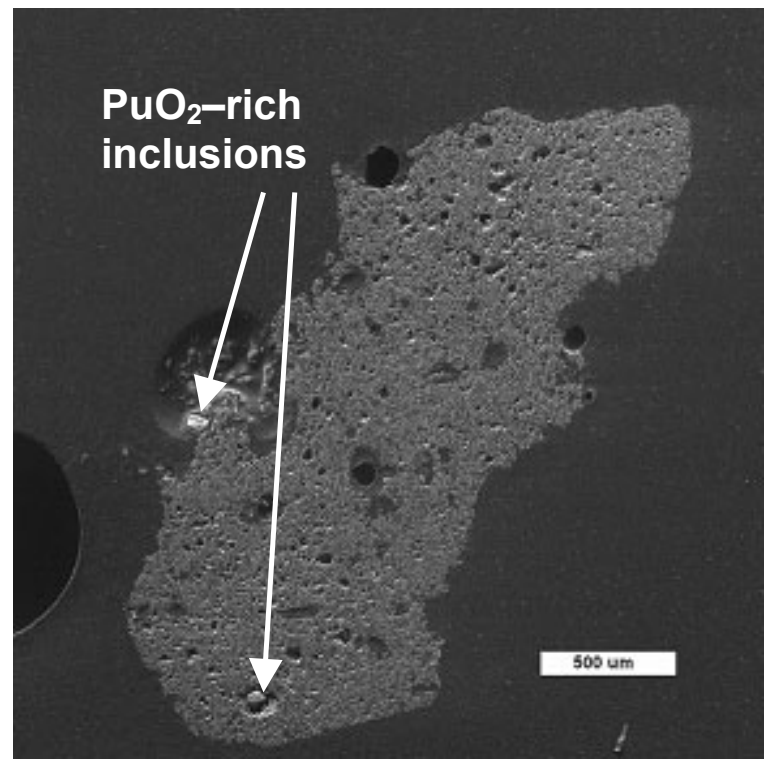

Fig. 3. SEM image of the $\mathrm{MgO}-\mathrm{ZrO}_{2}-\mathrm{PuO}_{2}$ ceramic sample submitted for analysis. The black area surrounding and black shapes within the sample are the mounting epoxy. The sample consists of a matrix and $\mathrm{PuO}_{2}$-rich inclusions. 
a)

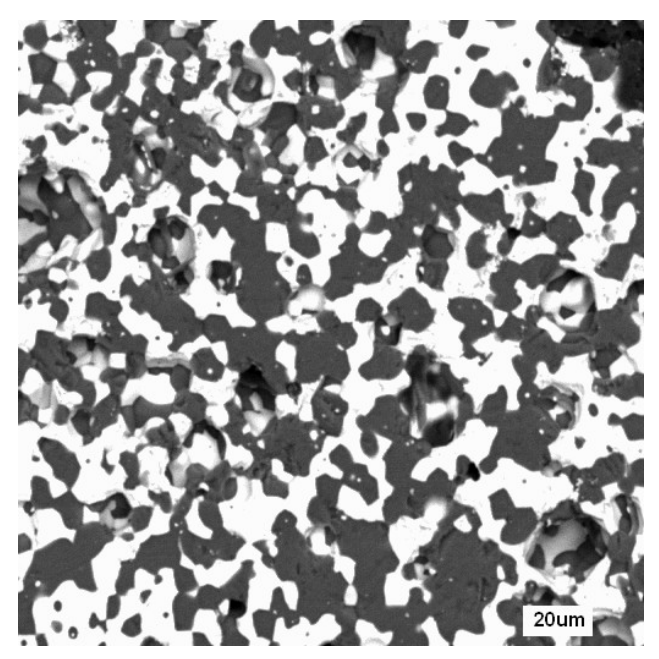

b)

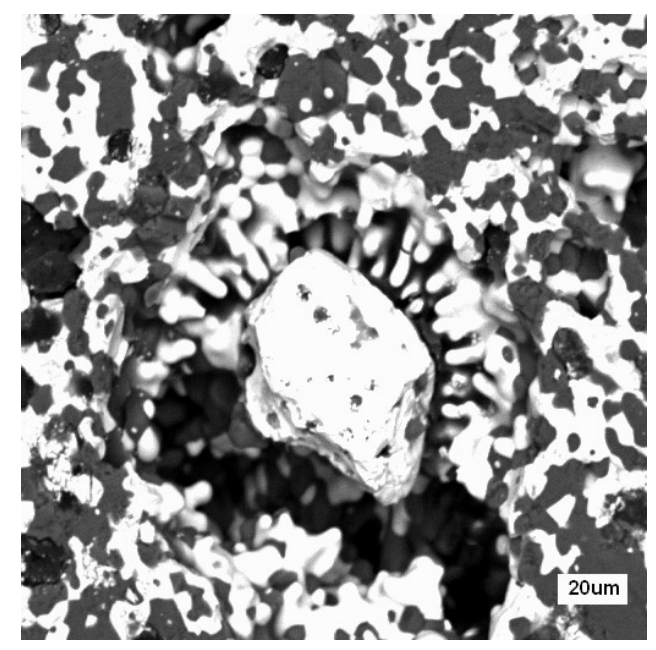

Fig. 4. Key microstructural features identified in the sample are a two-phase matrix (a) and a $\mathrm{PuO}_{2}$-rich inclusion (b). The matrix consisted of pure $\mathrm{MgO}$ phase (dark phase) and $\mathrm{MgO}-\mathrm{ZrO}_{2}-\mathrm{PuO}_{2}$ solid solution (light phase). The $\mathrm{PuO}_{2}$-rich inclusion contained $\mathrm{MgO}$ and $\mathrm{ZrO}_{2}$ with $\mathrm{PuO}_{2}$ being a dominant component. 

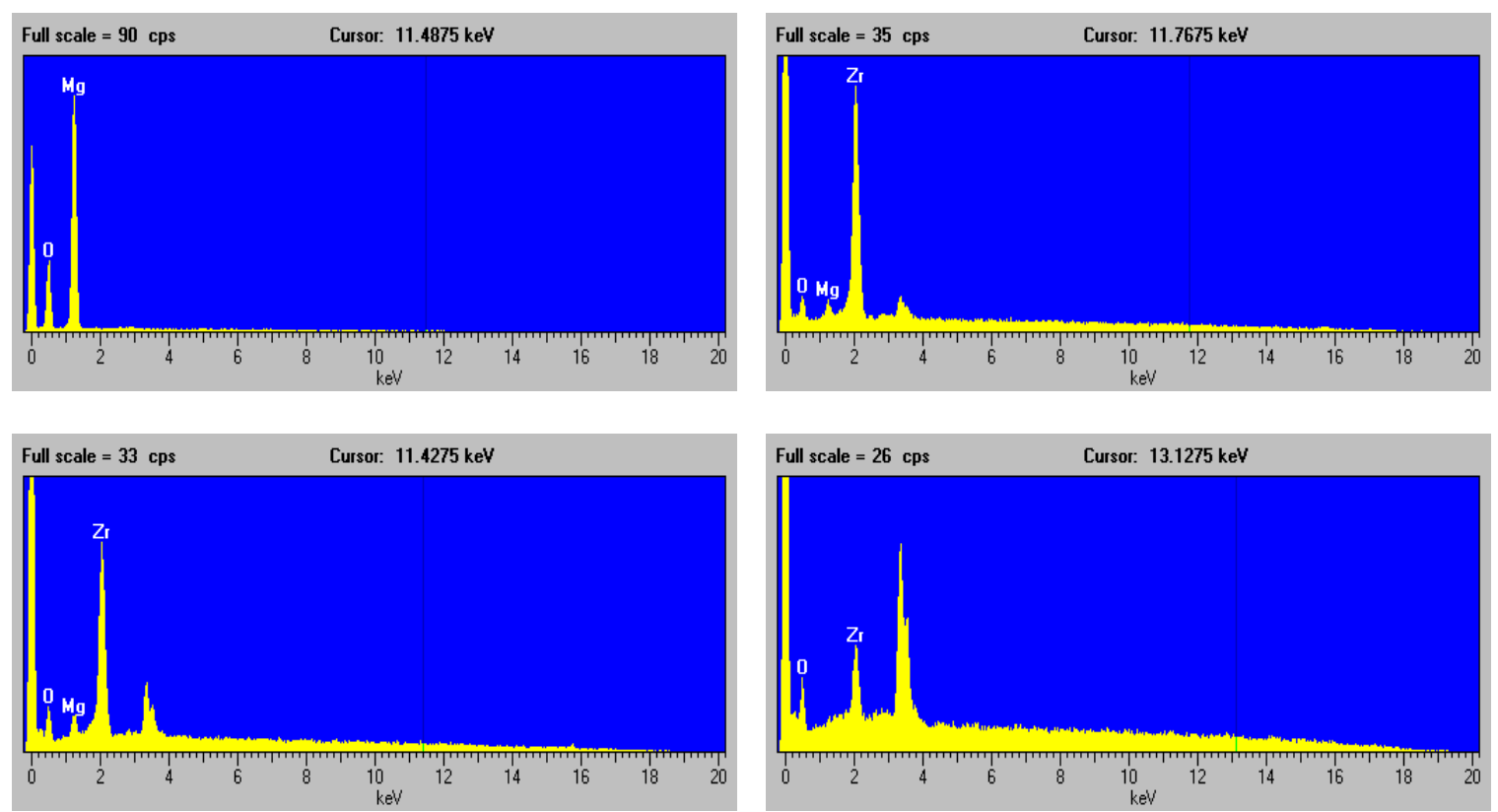

Fig. 5. Typical EDS spectra observed in various locations in the ceramic. 
Table 1.

Dimensions and weight of the sintered ceramic pellets.

\begin{tabular}{ccccccccc}
\hline \multirow{2}{*}{ Pellet } & Weight, $(\mathrm{g})$ & $\begin{array}{c}\text { Length, } \\
(\mathrm{mm})\end{array}$ & face & Did-pellet & face & average & \multicolumn{2}{c}{ Density, $\left(\mathrm{g} \mathrm{cm}^{-3}\right)$} \\
bulk & immersion \\
\hline 1 & 5.0406 & 13.00 & 11.59 & 11.40 & 11.60 & 11.53 & 3.71 & 3.8157 \\
2 & 2.9043 & 7.48 & 11.57 & 11.42 & 11.55 & 11.51 & 3.73 & 3.8751 \\
\hline
\end{tabular}


Table 2.

Results from SEM EDS semi-quantitative analysis. Note that the ISIS EDS system can not perform quantitative analysis for elements heavier than uranium.

\begin{tabular}{ccccc}
\hline Phase & $\begin{array}{c}\mathrm{Mg} \\
\text { (at. \%) }\end{array}$ & $\begin{array}{c}\mathrm{Zr} \\
\text { (at. \%) }\end{array}$ & $\begin{array}{c}\mathrm{O} \\
\text { (at. \%) }\end{array}$ & $\begin{array}{c}\mathrm{Zr} \text { to Mg } \\
\text { atomic ratio }\end{array}$ \\
\hline $\begin{array}{c}\mathrm{MgO} \\
\text { grains in matrix }\end{array}$ & $48.29 \pm 0.92$ & $0.06 \pm 0.04$ & $51.65 \pm 0.94$ & \\
$\begin{array}{c}\mathrm{MgO}-\mathrm{ZrO}_{2}-\mathrm{PuO}_{2} \\
\text { grains in matrix } \\
\begin{array}{c}\mathrm{PuO}_{2^{-}} \\
\text {rich inclusion }\end{array}\end{array}$ & $3.68 \pm 0.37$ & $23.19 \pm 1.10$ & $73.13 \pm 1.00$ & $6.38 \pm 0.83$ \\
\hline
\end{tabular}




\section{References}

[1] C. Degueldre, U. Kasemeyer, F. Botta, G. Ledergerber, Mater. Res. Soc. Symp. Proc. 412 (1996) 15-23.

[2] Ch. Hellwig and U. Kasemeyer, J. Nucl. Mater. 319 (2003) 87-94.

[3] T. Nakamura, H. Sasajima, T. Yamashita and H. Uetsuka, J. Nucl. Mater. 319 (2003) 95-101.

[4] C. Degueldre, J. Paratte, Nucl. Technol. 123 (1998) 21-29.

[5] C. Degueldre, T. Arima, Y. W. Lee, J. Nucl. Mater. 319 (2003) 6-14.

[6] K. Yasuda, C. Kinoshita, S. Matsumura and A. I. Ryazanov, J. Nuc. Mater. 319 (2003) 74-80.

[7] U. Kasemeyer, Ch. Hellwig, J. Lebenhaft and R. Chawla, J. Nucl. Mater. 319 (2003) 142-153.

[8] H. Akie, Y. Sugo and R. Okawa, J. Nucl. Mater. 319 (2003) 166-172.

[9] S. Lutique, R.J.M. Konings, V.V. Rondinella, J. Somers, T. Wiss, J. Alloys Compd. 352 (2003) 1-5.

[10] P.G. Medvedev, Development of dual-phase magnesia-zirconia ceramics for light water reactor inert matrix fuel, Dissertation, Texas A\&M University, 2004.

[11] P. G. Mardon, D. J. Hodkin, J. T. Dalton, J. Nucl. Mater. 32 (1969) 126-134. 